\title{
O PROCESSO DECISÓRIO EM CHARLES EDWARD LINDBLOM E A VONTADE GERAL EM JEAN-JACQUES ROUSSEAU: REFLEXÕES ACERCA DA PARTICIPAÇÃO POLÍTICA E DA NECESSIDADE DE EDUCAÇÃO PARA ESSA PARTICIPAÇÃO
}

\author{
EL PROCESO DE TOMA DE DECISIONES EN CHARLES EDWARD \\ LINDBLOM Y LA VOLUNTAD GENERAL EN JEAN-JACQUES ROUSSEAU: \\ REFLEXIONES SOBRE LA PARTICIPACIÓN POLÍTICA Y LA NECESIDAD DE \\ EDUCACIÓN PARA ESA PARTICIPACIÓN
}

\author{
THE DECISION-MAKING PROCESS IN CHARLES EDWARD LINDBLOM AND \\ THE GENERAL WILL IN JEAN-JACQUES ROUSSEAU: REFLECTIONS ON \\ POLITICAL PARTICIPATION AND THE NEED FOR EDUCATION FOR THAT \\ PARTICIPATION
}

\author{
Roberta Aline SBRANA ${ }^{1}$ \\ Flaviana Christine V. P. M. ASSUMPÇÃO ${ }^{2}$ \\ Joana Corrêa GOULART ${ }^{3}$ \\ Sebastião de Souza LEMES ${ }^{4}$
}

RESUMO: Na obra O Processo de Decisão Política, Charles Edward Lindblom tece reflexões acerca desse processo, destacando a relevância da participação política dos cidadãos em geral. Entretanto, esse autor alerta a necessidade da existência de uma educação que tenha como compromisso a formação de homens e mulheres para a participação social, pois somente a partir dessa educação tal participação poderá se efetivar. Do mesmo modo, na obra O Contrato Social, Jean-Jacques Rousseau apresenta considerações acerca da importância da participação do povo no processo de elaboração desse contrato, a qual ocorrerá por intermédio da "vontade geral". Mas essa participação implica a criação de uma educação voltada para a formação do homem como indivíduo e cidadão, para que este participe de forma ativa da sociedade, tal como expõe em seu tratado pedagógico - Emílio ou Da Educação. O intuito desse trabalho é evidenciar que em ambas as reflexões esses autores discutem sobre essa relevância da participação política dos cidadãos, a qual, segundo sua visão, será concretizada apenas pela existência de uma educação que valorize a formação para a participação.

${ }^{1}$ Universidade Estadual Paulista (Unesp), Faculdade de Ciências e Letras, Araraquara - SP - Brasil. Doutoranda no Programa de Pós-graduação em Educação Escolar. Membro do Grupo de Pesquisa Retórica e Argumentação na Pedagogia (USP/CNPq). E-mail: robertasbrana@ gmail.com

${ }^{2}$ Universidade Estadual Paulista (Unesp), Faculdade de Ciências e Letras, Araraquara - SP - Brasil. Coordenadora do Curso de Pedagogia do Campus Quirinópolis. Membro do grupo de Avaliação Permanente da UEG. Doutoranda no Programa de Pós-graduação em Educação Escolar. Colaborador do INEP/MEC. E-mail: fcristine@ uol.com.br

${ }^{3}$ Universidade Estadual de Goiás (UEG), Quirinópolis - Go - Brasil. Doutoranda no Programa de Pósgraduação em Educação Escolar. E-mail: joanacgoulart@gmail.com

${ }^{4}$ Universidade Estadual Paulista (Unesp), Faculdade de Ciências e Letras, Araraquara - SP - Brasil. Professor do Departamento Ciências da Educação e do Programa de Pós-Graduação em Educação Escolar. E-mail: ss.lemes2@gmail.com 
PALAVRAS-CHAVE: Processo decisório. Vontade geral. Participação. Educação.

RESUMEN: En el libro El Proceso de Decisión de Política, Charles Edward Lindblom teje reflexiones sobre este proceso, haciendo hincapié en la importancia de la participación política de los ciudadanos en general. Sin embargo, el autor advierte la necesidad de la existencia de una educación que se ha comprometido a la formación de hombres y mujeres para la participación social, porque sólo de la enseñanza recibida dicha participación puede ser eficaz. Del mismo modo, en la obra El contrato social, Jean-Jacques Rousseau presenta consideraciones acerca de la importancia de la participación popular en la elaboración del proceso de contratación, que se llevará a cabo a través de la "voluntad general". Pero esta participación implica la creación de una educación para la formación del hombre como individuo y ciudadano para que participe activamente en la sociedad, tal como se expone en su tratado pedagógico Emilio o la educación. El propósito de este trabajo es mostrar que en estas dos reflexiones autores discuten esta importancia de la participación política de los ciudadanos, que, en su opinión, sólo se logrará por la existencia de una educación que valore la formación para la participación.

PALABRAS ClAVE: Toma de decisiones. Voluntad general. Participación. Educación.

ABSTRACT: In The Policy-Making Process, Charles Edward Lindblom reflects upon such process, highlighting the relevance of the political participation of the general citizens. Nevertheless, the author warns the reader about the necessity of the existence of a kind of education that commits to the formation of men and women for social participation since, only because of this kind of education, such participation will be carried out. Likewise, in The Social Contract, Jean-Jacques Rousseau presents considerations about the importance of a people's participation in the elaboration process of such contract, which shall happen through "general will". Nonetheless, such participation entails a kind of education towards the formation of men as individuals and citizens in order for them to participate actively in society, as he exposes in his pedagogical treatise - Emile or On Education. This paper aims to foreground that, in both reflections, the authors discuss about the relevance of the political participation of the citizens, which, according to their point of view, shall fully happen only through the existence of a kind of education that values formation for participation.

KEYWORDS: Decision-making process. General will. Participation. Education.

\section{Introdução}

O presente trabalho focaliza as reflexões de Charles Edward Lindblom sobre o processo de decisão política apresentadas em sua obra homônima, e por Jean-Jacques Rousseau sobre a "vontade geral", conceito exposto em suas obras O Contrato Social e Emílio ou Da Educação. O intuito é evidenciar que em ambas as reflexões esses autores 
discutem sobre a participação política dos cidadãos e sua importância, bem como a necessidade de educação para que essa participação se concretize (ROUSSEAU, 2003, p. 47).

A escolha de Rousseau para essa relação se deve ao fato de que para Lindblom (1981, p. 116), o conceito de "vontade geral" apresentado por esse filósofo "elucida o processo de socialização política", além do "papel da análise como alternativa para a interação política", tal como abordado em sua obra. Ainda segundo Lindblom (1981), a leitura de "clássicos da filosofia política", como O Contrato Social, pode contribuir para "alargar nossa mente, na busca de ideias sobre o processo decisório".

Sobre esse "processo", Lindblom (1981, p. 85) explica em sua obra que ele abarca diferentes modalidades de participantes tais como os "cidadãos comuns, os líderes dos grupos de interesses, os legisladores, os ativistas de partidos, os magistrados e os servidores públicos", sendo que cada uma dessas modalidades exerce uma função especial nesse processo. As relações que se estabelecem entre esses participantes se constitui em um “jogo do poder", no qual os participantes responsáveis pela formulação das políticas públicas têm maior participação no processo decisório do que os "cidadãos comuns", ocasionando uma "desigualdade política" nessa participação.

Para que haja maior igualdade de participação nesse processo de decisão política, Lindblom (1981, p. 85) defende que os cidadãos em geral, e não apenas uma pequena parcela deles, como ocorre corriqueiramente, precisam desempenhar uma postura mais "ativa" socialmente. Para assumir essa postura e definitivamente "atuar como cidadãos", é necessário que os indivíduos aprendam a importância da "participação política"; para tanto é necessário que tenham acesso a uma educação que tenha como um de seus objetivos formar para a participação (LINDBLOM, 1981, p. 89).

Na obra $O$ Contrato Social, Rousseau (2003, p. 47) também defende a importância da participação dos cidadãos; ao apresentar as cláusulas que regem o contrato por ele concebido, esse filósofo prevê a mencionada participação no âmbito do poder legislativo, no processo de elaboração e definição das leis, as quais deverão ter como base a "vontade geral" que representa a coletividade dos cidadãos e não apenas o interesse particular de um homem, tal como ocorria na França e em outros países europeus no século XVIII.

Rousseau concebia que naqueles tempos modernos em que vivia, "tudo estava ligado à política", portanto, era necessário formar "bons cidadãos" para participarem 
ativamente do contrato social e das assembleias a fim de transformar a sociedade existente. Entretanto, uma formação que incentive a participação política "supõe uma boa educação" (BURGELIN, 2003, p. IX). Fundamentado nessa ideia o filósofo elabora seu "tratado sobre a educação" denominado Emílio ou Da Educação, que foi publicado no ano de 1762, dois meses após O Contrato Social. Para Valdemarin (2000, p. 41), esse "tratado pedagógico" pode ser caracterizado como uma das "faces daquele contrato político ou a face pedagógica da ação política".

Essas reflexões desenvolvidas por Lindblom e Rousseau, acerca da participação política dos cidadãos e sua importância, bem como da necessidade de uma educação que tenha como objetivo formar indivíduos para essa participação, serão explicitadas nas seções apresentadas a seguir. No entanto, para compreendermos a importância dessa participação é preciso, anteriormente, compreendermos como o processo decisório é concebido por Lindblom e como Rousseau define a "vontade geral" no Contrato Social.

\section{O processo decisório: sua origem e constituição}

Segundo Lindblom (1981, p. 7), ao longo da história diferentes autores como Platão, Hobbes e Rousseau se dedicaram a entender e a discutir sobre política; este último, ao questionar - "o homem nasceu livre e por toda parte ele está agrilhoado" (ROUSSEAU, 2003, p. 9), buscava solucionar esse impasse propondo uma nova forma de organização política a partir de um contrato social entre os homens. Apesar da importância de todos esses autores e seu pensamento para refletirmos sobre a política e as questões que a envolve, nenhum deles se dedicou a compreender e a falar especificamente sobre o processo de decisão política.

Apenas Adam Smith, "importante figura do pensamento social”, se dedicou a compreender e discutir tal processo, considerando sua "eficiência ou racionalidade, dando início a uma tradição intelectual". Em sua obra "Riquezas das Nações", Smith abordou as "deficiências da política comercial nos governos contemporâneos". Ele alvitrou que as "decisões sobre política econômica fossem retiradas das mãos dos governos e transferidas para o mercado" (LINDBLOM, 1981, p. 7).

Os estudos sobre o processo decisório e sua racionalidade ganharam evidência no âmbito da ciência política nos anos de 1980. Para compreender esse processo bem como "quem ou quê formula políticas" é necessário primeiramente "entender as características de seus participantes, os papéis que desempenham, a autoridade ou 
outros poderes que detêm, como lidam uns com os outros e se controlam", o que caracteriza as relações que constituem esse processo. É preciso também considerar que existem diferentes "modalidades de participantes", a saber: "cidadãos comuns, líderes dos grupos de interesses, legisladores, ativistas de partidos, magistrados, servidores públicos", sendo que cada um deles "exerce uma função especial" no mencionado processo (LINDBLOM, 1981, p. 7-8 grifos do autor).

Naqueles estudos, o método normalmente utilizado para compreender as complexidades do processo decisório consiste em uma análise isolada de cada um de seus componentes. Começa-se estudando "como surgem os problemas" que requerem uma decisão política e "como eles chegam às agendas das autoridades governamentais"; a seguir, busca-se compreender "como as pessoas formulam os temas da ação governamental, como se processa a subsequente a ação legislativa ou de outra natureza, e como os administradores aplicam a política escolhida"; por fim, no término do processo, busca-se compreender "como esta política pode ser avaliada" (LINDBLOM, 1981, p. 8-9).

Entretanto, como explica Lindblom (1981, p. 9-10), as pessoas que constituem esse processo são as mesmas em todas as etapas; as formas como elas "cooperam ou disputam entre si também não variam muita de uma etapa para outra"; além disso, é preciso considerar que alguns problemas constituem todas as etapas desse processo, por essa razão, uma "abordagem tópica" da decisão política que considera cada etapa separadamente, se "concentrando nos aspectos específicos da política, poderia obscurecer os fenômenos e temas universais" que a integram. Com esse tipo de análise ainda se corre o "risco de admitir que o processo decisório ocorre de modo ordenado, racional, tendo começo, meio e fim, estando cada parte associada logicamente às outras".

Para Lindblom (1981, p. 9-10), essa "premissa precisa ser contestada". As próprias características desse processo "depõem contra essa premissa". Basta considerarmos, por exemplo, que a "solução proposta por um grupo" para determinada política pode "representar um problema para outro grupo", gerando assim deliberações e "descontinuidades sobre sua implementação e inserção na agenda governamental". Nesse "canteiro da implementação nascem todo o tempo novos problemas de decisão política", os quais são "colhidos para a inclusão na agenda". É nesse sentido, que o processo decisório tem um "caráter desordenado", sendo algo "extremamente complexo, sem princípio nem fim, cujos limites são incertos”. 
Nessa linha de pensamento, considera-se o "governo e a política integralmente como um processo de decisão", não incorrendo, portanto, naquele "erro de ver a decisão política" apenas como "um aspecto da política", tal como quando este processo é examinado a partir da divisão em etapas. A compreensão do que acontece no processo decisório requer "entender a atividade política no seu conjunto". Uma compreensão satisfatória desse processo, dos "fatos fundamentais" que o constituem no "campo da política", permite "empreender sua avaliação", que por vezes, pode ser "inconclusiva", mas precisa ser realizada (LINDBLOM, 1981, p. 10-11 grifos do autor).

Segundo Lindblom (1981, p. 12), é preciso considerar que o processo decisório bem como as políticas e os seus resultados assumem características distintas em diferentes sistemas, tal como nos democráticos e autoritários, na medida em que esses últimos, não apresentam, por exemplo, "políticas destinadas a garantir as liberdades civis". Entretanto, mesmo o processo decisório se constituindo de forma distinta nesses sistemas, os resultados alcançados não apresentam diferenças significativas.

Essas diferenças se manifestam, primordialmente, no âmbito socioeconômico e nas "ambições" que as "elites dominantes e a massas" dos diferentes países e seus sistemas "parecem desejar", tais como "a ordem e o império da lei, a produção agrícola e industrial, a mobilidade e comunicação". Acredita-se que com a realização dessas "ambições" será possível alcançar melhores condições de vida e "novas aberturas na pesquisa, educação e exploração". Desta forma, são essas "ambições" que "explicam por que os governos adotam determinadas políticas, e almejam certos resultados", e não o processo decisório; este, pode apenas explicar "como os governos procuram atingir seus vários objetivos, mas não por que escolhem esses objetivos" (LINDBLOM, 1981, p. 12, grifos do autor).

\section{O processo decisório na democracia: a participação política dos cidadãos requer educação}

Nos sistemas democráticos o processo de decisão política tem sido abordado por intermédio de dois problemas principais - "como tornar as políticas mais efetivas e como tornar o processo decisório sensível ao controle popular". O primeiro problema envolve questões como: "há o debate das políticas governamentais, o governo é mesmo ineficiente, como combater os erros existentes e aprimorar o nível de aperfeiçoamento 
desse processo, a ciência pode ajudar?"; sobre o segundo problema, alguns temas abordados são: "quem formula a política governamental, as elites influenciam diretamente, o cidadão tem influência, esta poderia ser aumentada, as eleições são importantes, importa qual partido vence a disputa eleitoral?" (LINDBLOM, 1981, p. 7$8)$.

Como solução àquele primeiro problema, muitos cidadãos acreditam que é necessário aumentar a informação, a reflexão e a análise no processo de decisão política. Sem dúvida, é preciso que haja uma ampla disseminação das informações e das análises realizadas; contudo, a sobrevalorização desta análise pode acarretar a "redução do conflito político", das deliberações no processo decisório pois elas representam um “obstáculo” à sua realização. E para solucionar o segundo problema, ou seja, aumentar o controle popular e sua participação nesse processo é necessário que a decisão política se “mantenha sempre como um processo 'político', isto é, prevalecendo a participação dos cidadãos nas discussões inerentes ao processo decisório (LINDBLOM, 1981, p. 13).

Alguns pensadores políticos defendem que numa sociedade democrática "a competição de ideias" é a solução mais viável para o processo decisório; outros autores, no entanto, por não "confiarem na política democrática", argumentam que esse caminho pode ser "perigoso", pois essa competição gera "mais conflito do que razão" no mencionado processo. É nesse sentido que "subexiste o conflito entre a razão, a análise e a ciência de um lado; a política e a democracia de outro". Assim, afirmam que se o intuito de uma sociedade é "aumentar o nível da razão e da análise do processo decisório talvez ela precise abandonar alguns aspectos da democracia" (LINDBLOM, 1981, p. 14 grifos do autor).

Para Lindblom (1981, p. 14-15), contrariamente, nesse "conflito entre a análise e a política no processo decisório" é preciso considerar que há a "possibilidade de que as duas, pelo menos em parte, se complementem mutuamente", pois a análise apresenta uma "ubiquidade", ou seja, ela está presente em todo processo de decisão política e, mesmo que as atividades envolvam discussões e "análises apressadas ou superficiais", gerando resultados questionáveis, a análise e a deliberação nunca estão ausentes nesse processo.

Apesar de sua importância, a análise não é capaz de responder aos diferentes problemas, interesses e poderes existentes no processo de decisório, os quais somente se 
resolvem a partir de debates, acordos e negociações, ou seja, pela "política". 5 A análise apresenta alguns limites, a saber: a "falibilidade" - ela não consegue abarcar a complexidade que envolve o ser humano e as sociedades, visto que ambos mudam constantemente; "conflitos de valor" - ela "não pode resolver tais conflitos" inerentes ao processo decisório; "tempo e custo" - uma análise séria exige tempo e consequentemente custos para ser realizada, e às vezes as exigências para que uma decisão seja tomada não pode esperar o tempo que a análise demanda; e "a identificação dos problemas" - a análise não pode determinar, de modo conclusivo, quais problemas precisam ser abordados (LINDBLOM, 1981, p. 20).

Diante dessas limitações apresentadas pela análise, Lindblom (1981, p. 25) aponta que o processo de decisão política nos sistemas democráticos pode ocorrer por meio da "política"; o que significa que a escolha de uma política pública a ser implantada ocorreu mediante a participação, a interação entre os cidadãos, pois estes "agem uns sobre os outros" reciprocamente. Essa forma de definir uma política substitui a análise pela ação para solucionar um problema; esta ação é exercida pelos cidadãos a partir de atos como, por exemplo, a votação nas eleições, ou mesmo pela pressão ou negociação exercida pelos candidatos em relação aos eleitores. Contrariamente, quando o processo decisório ocorre pela análise, a escolha da política pública a ser implantada ocorre por meio de uma investigação que aponta as "razões" pela qual devemos optar por uma política e não por outra.

Para Lindblom (1981, p. 26), no processo decisório a “interação política pode sempre substituir a análise" alcançando frequentemente resultados que esta última não atinge, pois a interação, que requer a participação política dos cidadãos permite conciliar as diferenças existentes como ocorre, por exemplo, na decisão sobre qual política deve ser adotada para melhorar a educação; neste caso, a análise não permitir chegar à uma decisão que contemple as diferentes opiniões dos cidadãos, mas a partir de um "método de interação, de participação como a votação", é possível definir qual política será adotada mesmo diante da diferença de opiniões dos participantes do processo decisório.

Por ser limitado, o "papel da análise" no processo decisório precisa ser complementado pela participação política. Desta forma, a análise deve ser considerada a partir de uma "perspectiva diferente", isto é, como "parcial, partidária ou sectária",

${ }^{5}$ Lindblom (1981) utiliza o termo "política" entre aspas para designar o debate, a discussão, a participação política dos cidadãos no processo decisório. 
sendo empregada como um "instrumento de controle no processo de interação política". Este tipo de análise é "parte da política", àquela análise apresentada anteriormente, é uma "alternativa para a política", sendo um componente crucial na elaboração das políticas (LINDBLOM, 1981, p. 29, grifos do autor).

Nas sociedades democráticas a análise parcial é comumente empregada no processo decisório. Quando o presidente propõe, por exemplo, uma política educacional ao congresso, cada participante do processo de decisão que se instaura irá defender seu ponto de vista, seus interesses. Mesmo que cada participante empregue uma análise ou reflexão para defender os próprios interesses, haverá inevitavelmente uma "interação com as outras partes" que farão o mesmo. Cada uma dessas análises apresentadas nesse processo decisório se tornará "patrimônio comum de todos os participantes", que poderão "contestá-la ou usá-la"; se a análise se mostrar "útil" para solucionar aquele problema político, ela poderá ser adotada por todos, se for "prejudicial, poderá ser neutralizada" com base em outras que concorrem com ela. Esse "intercâmbio" entre diferentes análises parciais se constitui na "competição de ideias, considerada essencial" nos sistemas democráticos (LINDBLOM, 1981, p. 30).

Nessa interação para definir as políticas, os participantes do processo decisório exercem "controle, influência e poder uns sobre os outros". A própria análise que utilizam para defender seus interesses é um método para exercer controle. Há vários "processos de controle por interação" utilizados por esses participantes como "a persuasão, a ameaça, a autoridade", os quais se dão em um “jogo do poder", no qual as "pessoas se influenciam reciprocamente, resultando em um conjunto de inter-relações mais complexas do que o termo genérico 'política', ou o simples 'interrelacionamento"” (LINDBLOM, 1981, p. 39).

Os responsáveis por formular as políticas e os cidadãos comuns são “elementos fundamentais desse jogo do poder". Os primeiros constituem uma elite formada por uma pequena parcela da população composta por "autoridades executivas, ministros, congressistas, altos funcionários públicos, funcionários do Poder Judiciário, chefes políticos e dirigentes partidários". Os cidadãos, que constituem a maior parcela da população, compõem o "grupo mais importante" dos participantes desse "jogo", entretanto, participam dele com uma força menor (LINDBLOM, 1981, p. 39-40).

O "jogo do poder" nos sistemas democráticos inclui "traços adicionais", visto que a democracia é caracterizada por um "conjunto especial de regras que prescreve" que a escolha de algumas autoridades deve ser feita segundo o "critério de preferência 
dos cidadãos"; estas regras dependem de outras, como a "livre manifestação de ideias, a faculdade de reunião dos cidadãos, bem como a ampla elegibilidade". Todas essas regras afetam diretamente o mencionado "jogo" no processo de decisão política, pois elas contribuem para "dispersar o controle exercido sobre tal processo", permitindo que todos os adultos participem da escolha das autoridades por meio do voto ou se candidatem aos cargos existentes, além de conceder a todos a "liberdade de exprimir opiniões políticas" (LINDBLOM, 1981, p. 51).

Apesar de as regras democráticas concederem aos cidadãos "importantes poderes e liberdades", elas ainda não permitem um "controle muito eficaz sobre a decisão política", pois, não há uma "relação direta entre o que os cidadãos desejam e as políticas que se obtêm”, pois estas são “definidas a partir da estrutura de regras, relações de poder, procedimentos e organizações existentes entre os candidatos eleitos”. Além disso, os "formuladores de políticas promovem arranjos" que contemplam inicialmente seus interesses e não a "ampliação da eficácia do controle popular" (LINDBLOM, 1981, p. 57).

Embora as regras democráticas ampliem a participação popular, ainda é necessário que haja na sociedade uma elite incumbida das decisões políticas. Uma “complicação" apresentada pela "política democrática têm origem na deliberada divisão e sobreposição de autoridade" fazendo com que os diferentes participantes do "processo de decisão política se especializem e, ao mesmo tempo, interfiram uns com os outros", o que dificulta a tomada de decisão no processo político. A divisão dos poderes legislativo, executivo e judiciário, comum nas democracias, visa impedir a concentração excessiva da autoridade e a garantia da liberdade para todos (LINDBLOM, 1981, p. 53).

Entretanto, no "jogo do poder" a maioria dos cidadãos comuns participam com "pouca frequência, desempenhando papéis menores". Se sua intenção é "exercer controle sobre o processo decisório eles enfrentam inúmeras dificuldades" como a "multiplicidade de participantes nas atividades políticas, a espantosa variedade de delegações de autoridade, os procedimentos destinados a proteger a liberdade dos cidadãos e não o controle popular na decisão de alguns assuntos"; além disso, a “posição privilegiada dos empresários e as vantagens que possuem no exercício de sua atividade de grupo de interesse", reduzem ainda mais a "possibilidade de controle popular" nesse "jogo" aumentando a "desigualdade política" entre os participantes, que também contribui para obstruir aquele controle (LINDBLOM, 1981, p. 85). 
Para Lindblom (1981, p. 86), essa "desigualdade" caracterizada como "desigualdade imposta", não anula o controle exercido pelos cidadãos naquele "jogo", mas contribui para que "alguns deles exerçam maior controle que outros". Por outro lado, a "norma da igualdade política" existente nos sistemas democráticos prevê não somente o "controle pelos cidadãos, mas igual distribuição entre eles dos direitos e capacidades de controle". Entretanto, diante das diferenças sociais e econômicas existentes entre os cidadãos, os "grupos favorecidos" discordam desta norma com vistas a defender seus interesses; eles alegam que o processo de decisão política não deve ser conduzido por todos os cidadãos, mas apenas por aqueles que têm conhecimento "competente" para tal, ou seja, os "formuladores de políticas"; outros grupos consideram que para além da "igualdade ou desigualdade no processo decisório" há questões mais importantes, como torná-lo "mais adaptável, capaz de inovação" ou mesmo com "maior continuidade e estabilidade".

É nesse sentido, que a "igualdade política não é um critério bem aceito ou definido" no processo decisório, e a "desigualdade política influencia a capacidade do cidadão de controlar tal processo". Além dessa "desigualdade imposta" é preciso também considerar a existência nos sistemas democráticos de "desigualdades básicas" entre os "grupos favorecidos" e os "cidadãos comuns", as quais apontam a esses últimos "poucos motivos para participar ativamente da política". Essas "desigualdades" estão diretamente ligadas "à renda e ao status" que cada cidadão possui; quanto menor forem esses elementos, menor será a participação do cidadão, pois ele enfrenta dificuldade "na propensão e busca de informação acerca da política, de seus candidatos e temas"; essa dificuldade ainda está ligada a uma "questão mais profunda", ou seja, à "desigualdade educacional" que esses cidadãos pertencentes às classes menos favorecidas possuem em relação aos que integram os "grupos favorecidos" (LINDBLOM, 1981, p. 87).

A difusão dos meios de comunicação e da internet ao longo dos séculos XX e XXI contribuiu para que os cidadãos de diferentes classes sociais tivessem maior acesso às informações, dentre as quais se incluem as questões políticas. Entretanto, como explica Lindblom (1981, p. 89), a compreensão e a "familiaridade" com tais questões, que propicia a "participação política", estão diretamente ligadas ao "nível de instrução" adquirido por esses cidadãos; aqueles que possuem "maior lastro educativo participam mais intensamente"; em contrapartida, aqueles que possuem "menores rendas e status" e consequentemente "baixos índices de escolaridade" frequentemente não "buscam 
informações sobre a política por não verem sentido ou possibilidade de efetiva participação".

A participação política e a "adoção de estratégias destinadas a conquistar influência pessoal no jogo do poder estão inescapavelmente fora do alcance" daqueles cidadãos que "não conseguiram educar-se". A ausência de participação da maioria dos cidadãos no "jogo do poder" está no fato de que eles "não foram ensinados, doutrinados ou socializados, neste sentido". Há que se considerar que as pessoas possuem "participação política se aprenderam a aceitar sua importância, se aprenderam a atuar como cidadãos", bem como "se foram doutrinadas nas aspirações e expectativas que estimulam ao invés de paralisar, se aprenderam a se considerar membros de uma comunidade política” (LINDBLOM, 1981, p. 89).

A "participação política" se aprende na escola bem como por meio da participação e das relações que os cidadãos estabelecem com os diferentes atores e instituições sociais, tais como a "família, os amigos, os clubes e partidos políticos", os quais também são responsáveis por desenvolver "atitudes e disposições para a ação" impulsionando esses indivíduos a "participar da vida política de várias formas", sendo uma delas a votação nas eleições. Por essa razão, além da educação, o cidadão precisa ser "socializado", senão ele "não vota e não participa do processo decisório" (LINDBLOM, 1981, p. 89).

Além do voto, outras formas que os cidadãos têm de participar desse processo e consequentemente do "jogo do poder" que o constitui é por meio de protestos, reivindicações e greves a fim de garantir os recursos e direitos necessários à sua vida, como alimentação, educação, saúde, segurança, moradia e remuneração justa. Entretanto, essas formas de participação assumem, por vezes, uma imagem pejorativa construída principalmente pela mídia que as apresenta como meios utilizados pelo trabalhador para não realizar suas atividades, ou mesmo como desnecessários, alegando que os trabalhadores já possuem os recursos devidos para realização da atividade que lhe compete; assim, essas formas de participação acabam sendo ignoradas e até criticadas pelos cidadãos, que não tendo recebido uma educação, uma formação que incentivasse sua participação política, não entendem o sentido, a importância dessa participação (LINDBLOM, 1981, p. 39-40).

Para ilustrar essa situação podemos citar as greves realizadas pelos professores das diferentes etapas da educação, ou mesmo a greve em que a Universidade Estadual Paulista "Júlio de Mesquita Filho" - UNESP está passando atualmente; além das 
críticas expostas pela mídia que apresenta a greve como desnecessária, e em algumas situações como forma de bagunça, como atitude de quem não quer trabalhar, deturpando a imagem e o sentido desse direito do trabalhador, os próprios profissionais e no caso da Universidade, os alunos, por não terem recebido uma educação que valorizava a participação política, lhes mostrando seu significado e importância, acabam também desenvolvendo uma visão negativa dessa forma de participação e assumem uma postura contrária ou indiferente em relação a ela. Apesar de a maioria das escolas apresentarem em seu Projeto Político Pedagógico a finalidade de formar cidadãos, a participação ainda é pouco ensinada, incentivada no cotidiano escolar, o que torna a participação política dos cidadãos escassa.

Assim, mesmo sendo a educação um fator preponderante para desenvolver e ensinar aos indivíduos a importância da "participação política", muitas escolas apresentam "uma falha séria" - a "socialização positiva contra a participação", ou seja, a "não participação"; nesse caso, ao invés de ensinar a importância dessa participação e mostrar seu sentido, as escolas a "desencorajam, induzindo os alunos à se submeterem à autoridade" the imposta. Tal formação contribui para que os cidadãos assumam uma postura passiva frente às questões políticas inerentes à sua realidade, ao invés de participarem ativamente das decisões do processo político. Sua participação ocorre normalmente pelo voto, o qual de certo modo, exerce alguma influência, denotando assim uma postura que não é totalmente passiva (LINDBLOM, 1981, p. 89 grifos do autor).

Contudo, a efetiva participação no "jogo do poder" implica não somente a possibilidade de votar, mas de possuir "conhecimento dos assuntos políticos, capacitação na análise parcial, persuasão, status na comunidade, aliados influentes e êxito nas relações interpessoais". Porém, somente um pequeno número de cidadãos com altos níveis de escolarização é que possuem essas "vantagens" e habilidades; a maioria da população fica alheia a essas "vantagens". Além disso, a "participação na escolha das autoridades governamentais e a influência sobre elas" requer uma "organização" por parte dos cidadãos, pois "sozinhos, eles pouco podem fazer", o que implica sua participação em “organizações e grupos de interesse"; no entanto, para essa participação são exigidas àquelas "vantagens", que normalmente, os cidadãos não possuem (LINDBLOM, 1981, p. 90 grifos do autor).

Assim, é evidente que as "desigualdades de informação, educação e socialização" que "convergem" entre si, contribuem para que os cidadãos apresentem 
"grandes diferenças na capacidade pessoal para compreender o jogo do poder", e na sua participação política nesse "jogo", o que contribui para que desenvolvam "a crença de que podem influenciá-lo" e que o "modo como dele participam é eficaz" (LINDBLOM, 1981, p. 89-90).

\section{A "vontade geral" em O Contrato Social}

Como explica Valdemarin (2000, p. 36), ao escrever o Contrato Social, Rousseau tem como "objeto" conhecer como "legitimamente pode se dar a passagem da liberdade natural, que atende aos impulsos naturais do indivíduo em seu estado natural ${ }^{6}$, para a liberdade convencional", que é oriunda da "vida em sociedade", enfrentando assim o impasse de que "o homem nasceu livre e por toda parte ele está agrilhoado" pelas convenções advindas da desigualdade social (ROUSSEAU, 2003, p. 9).

Embora muitos autores considerem a política uma "arte de forjar esses grilhões", Rousseau a concebe como uma "arte" que nos "libertar deles"; sua "preocupação" é que a política seja para o homem um "meio de se fazer e não de se corromper" (BURGELIN, 2003, p. XII). Sem desconsiderar a política como uma "arte de administrar uma sociedade", ou "de conquistar ou conservar o governo", Rousseau entende que ela é uma "arte do possível", que se constitui em "primeiro lugar como uma moral" que "realiza o homem". Nessa obra, o filósofo não objetiva "estudar a política em si mesma, mas determinar seu fundamento, os "princípios do direito político", sendo este o subtítulo da referida obra. A preocupação de Rousseau é a "natureza e a felicidade humanas", e nesse "trajeto encontra necessariamente a política" (BURGELIN, 2003, p. X-XI).

Para Rousseau (2003, p. 20), o "pacto social” tem início quando os "obstáculos prejudiciais à conservação" do homem em seu "estado de natureza sobrepujam pela resistência, as forças que cada indivíduo" possui para se "manter nesse estado". Era preciso conservar as "vantagens da vida coletiva", sem, no entanto, "gerar desigualdade" (VALDEMARIN, 2000, p. 38). Para tanto, é necessário resolver o seguinte problema formulado pelo filósofo: "Encontrar uma forma de associação que

${ }^{6}$ Esse "estado natural" compreende o momento em que o homem ainda vivia em um "estado primitivo" movido por seus impulsos de sobrevivência, quando ainda não havia sido criada a sociedade civil, tal como apresentado por Rousseau, em seu Segundo Discurso - Discurso sobre a origem e os fundamentos da desigualdade entre os homens (1999). 
defenda e proteja com toda a força comum a pessoa e os bens de cada associado, e pela qual cada um, unindo-se a todos, só obedeça, contudo, a si mesmo e permaneça tão livre quanto antes" (ROUSSEAU, 2003, p. 20-21).

A "solução" para este problema é "fornecida pelo contrato social". Quando "bem" entendidas as cláusulas que compõem esse contrato, elas "se reduzem todas a uma só", ou seja, "a alienação total de cada associado, com todos os seus direitos, a toda a comunidade"; o que significa, que "cada qual dando-se por inteiro, a condição é igual para todos, e, sendo a condição igual para todos, ninguém tem interesse em torná-la onerosa para os demais" (ROUSSEAU, 2003, p. 21).

Essa cláusula do contrato "garante a liberdade para cada um dos homens que se associam". Contudo, é preciso ter cautela para não incorrer em "leituras equivocadas". Quando Rousseau fala da necessidade de "dar-se à comunidade", ele não se refere ao "desaparecimento do indivíduo e o totalitarismo do todo, do Estado, da massa", como, por vezes, se interpreta; "alienar seus direitos em favor da comunidade" significa "reconhecer como direitos seus apenas e tão somente aqueles que serão conferidos pela sociedade" (FRANCISCO, 2010, p. 31).

Esse "pacto social” idealizado por Rousseau é o "único que conserva a liberdade do homem, preservando-a no estado de dependência que é o da sociedade". Apesar de "alienar a si e os seus direitos em favor da comunidade" e se colocar "à inteira mercê da vontade geral", cada indivíduo "será na comunidade não apenas um súdito, submetido" a essa vontade, mas será também "participante da autoridade soberana, com direito" para defini-la (FRANCISCO, 2010, p. 31). A partir de então, cada homem, se constituirá como "súdito e soberano", e como participante dessa comunidade ele será um “cidadão", pois como afirma Rousseau (2003, p. 110), "as palavras súdito e soberano são correlações idênticas cuja ideia se reúne numa única palavra - cidadão".

Ao invés de submissão, a "vontade geral" garante aos cidadãos a participação política na comunidade, visto que ela se constitui como um "admirável acordo entre o interesse e a justiça" pautado nas deliberações entre todos os integrantes do "pacto social", as quais assumem "um caráter de equidade" que é inexistente em discussões que tratam de questões particulares, pois "falta um interesse comum" que una todos esses participantes. O predomínio dessa "vontade" nesse "pacto" ainda permite a socialização dos cidadãos (ROUSSEAU, 2003, p. 41).

Contudo, "há muita diferença entre a vontade de todos e a vontade geral"; esta última "se refere somente ao interesse comum, enquanto a outra diz respeito ao interesse 
privado" sendo, portanto, a "soma das vontades particulares". Porém, quando se "retiram dessas vontades particulares os mais e os menos que se destroem mutuamente, resta como soma das diferenças a vontade geral” (ROUSSEAU, 2003, p. 37). Deste modo, essa "vontade traduz o que há de comum nas vontades particulares" bem como o "interesse de cada um submetido ao corpo coletivo", o que implica considerar o "substrato comum a todos", não se referindo à "maioria numérica que representa o interesse de um número maior de indivíduos" (VALDEMARIN, 2000, p. 40).

A participação dos cidadãos assegurada pela "vontade geral" permite então "o acerto das vontades" produzindo "consensos tácitos que legitimam a vida democrática". Nesse modo de vida, caracterizado pela "associação dos particulares entre si” tem origem a "soberania absoluta", que será dirigida por aquela "vontade" que é "popular e legítima, inalienável e indivisível". Por meio dessa "soberania”, representada pela figura do "povo", é fundado o Estado, que também se constitui como "soberano" porque ao mesmo tempo em que "expressa a vontade geral, ele impede a dependência pessoal". Essa "condição constitui o artifício e o jogo de toda máquina política", que é a "única a legitimar os compromissos civis, os quais, sem isso se tornariam absurdos, tirânicos e sujeitos aos maiores abusos" (BOTO, 2010, p. 14-15).

Para Rousseau (2003, p. 33), somente a "vontade geral pode dirigir as forças do Estado em conformidade com o objetivo de sua instituição, que é o bem comum". Assim, o "vínculo social é formado pelo que há de comum" nos diferentes interesses dos cidadãos, pois "se não houvesse um ponto em que todos esses interesses concordassem, nenhuma sociedade poderia existir". É com “base nesse interesse comum que a sociedade deve ser governada". Quando a sociedade é organizada pelo "crivo da vontade geral", o "pacto civil" estabelecido entre os homens "ganhará uma tonalidade moral"; assim, se o contrato inclui a todos, "cada um sabe-se senhor de si" e de suas ações (BOTO, 2010, p. 14-15).

Assim, nesse "Estado soberano" a "vontade geral" se constitui como o "limite da sociedade civil"; o "liame social" é constituído a partir do "interesse comum" substituindo, por uma "igualdade moral e legítima" o que a natureza poderia trazer de "desigualdade física entre os homens", tornando-os "iguais por convenções e direitos" (ROUSSEAU, 2003, p. 39). Esse Estado criado por Rousseau no Contrato Social se diferencia daquele “ideário do contratualismo" existente no século XVIII na França, em que o "poder era necessariamente concedido, mediante a submissão de todos a um ou a alguns poucos homens" (BOTO, 2010, p. 14). 
Nessa sociedade pautada no "contrato social" e dirigida pela "vontade geral", os "compromissos" entre os cidadãos e o "corpo social" são "mútuos", o que significa que quando um cidadão "beneficia a si próprio, todos os demais serão beneficiados". Diante da "igualdade" estabelecida pelo "pacto social" todos os cidadãos se "comprometem nas mesmas condições e usufruem dos mesmos direitos", visto que se trata de uma "convenção" estabelecida entre "o corpo político e cada um de seus membros"; a "conservação" dessa convenção está inscrita na legislação, que visa promover a "união entre os direitos e deveres", os quais serão "mediados pelo esclarecimento" (VALDEMARIN, 2000, p. 40).

Ao definir a "vontade da comunidade em que se submeterá", o homem se "submete à sua própria vontade"; para Rousseau, ser livre, nada mais é que "obedecer à própria vontade e não a vontade de outrem” (FRANCISCO, 2010, p. 31). Essa "proposta" apresentada pelo filósofo de que "ser livre é poder dispor de seus bens sem prejudicar os outros", representa um "avanço nas formulações liberais", pois acrescenta um "mecanismo que impede que deste exercício" da liberdade, "surja a dependência" da "vontade individual" em relação a "vontade geral"; segundo suas proposições, o homem é "livre embora submetido a leis", entretanto, estas leis devem ser "formuladas a partir da participação livre de cada cidadão", isto é, a lei deve ser um "mecanismo de captação da vontade coletiva" (VALDEMARIN, 2000, p. 39).

\section{A participação no poder legislativo pela "vontade geral" implica em educação}

No Contrato Social o "objeto das leis é sempre geral", visto que a "lei considera os súditos coletivamente e as ações como abstratas, nunca um homem como indivíduo e uma ação particular”. A lei é "tão geral quanto a vontade que a estatui”, sendo, portanto, "atos da vontade geral" que serão formulados a partir da deliberação entre os cidadãos, o que resulta em sua socialização; é nesse sentido, que as leis representam as "condições da associação civil’. Ao mesmo tempo em que se submetem a elas, os cidadãos deverão ser os seus autores, pois "somente aos que se associam" a esse "contrato" cabe a responsabilidade de "regulamentar as condições da sociedade" (ROUSSEAU, 2003, p. 47-48).

Por assegurar a participação política dos cidadãos e se constituir a partir da “vontade geral”, Rousseau (2003, p. 45), afirma que a legislação dá "movimento e 
vontade ao pacto social". Deste modo, em uma "legislação perfeita a vontade particular ou individual deve ser nula", a "vontade do corpo ou do governo" deve ser "muito subordinada" e a "vontade geral ou soberana" deve "sempre ser dominante", concebida como "única regra de todas as outras" (ROUSSEAU, 2003, p. 78).

Na sociedade civil pautada naquele "contrato", o principal objetivo da legislação é a "preservação da liberdade e da igualdade", pois a "essência do corpo político reside no acordo entre a obediência e a liberdade" (ROUSSEAU, 2003, p. 62-63). Contudo, essa "lei estabelecida pela vontade geral" não irá garantir a todos os cidadãos "igualdade em termos de riqueza e poder"; essa "igualdade" se dará entre eles e o Estado, regulamentando para que tudo ocorra "de acordo com as regras aceitas" a fim de impedir a "violência" entre os cidadãos e garantir-lhes as "condições necessárias" para desfrutar igualmente da liberdade (VALDEMARIN, 2000, p. 41).

Responsáveis pela formulação das leis, os cidadãos exercem sua participação política no âmbito do poder legislativo, que também é regido pela "vontade geral", pois “pertence ao povo, e só a ele pode pertencer"; seu objeto nunca é individual, mas coletivo. Esse poder, aliado ao poder executivo, que "não pertence ao conjunto dos cidadãos", pois se destina somente a "atos particulares" que não competem à "alçada da lei", constituem o governo, "um corpo intermediário" que estabelece a "comunicação entre os cidadãos e o Estado" a fim de permitir sua "mútua correspondência"; esse “corpo" ainda é responsável pela "execução das leis e manutenção da liberdade, tanto civil como política" dos cidadãos, o que afiança sua participação na sociedade (ROUSSEAU, 2003, p. 71-72).

Entretanto, para que essa participação política fosse efetiva e garantisse a existência do "pacto social" Rousseau reconhece a necessidade de organizar uma "boa educação", que não existia na França no século XVIII; a "política implica antes de tudo a educação do cidadão", a qual permitirá a formação de "homens esclarecidos que não se deixarão enganar por insidiosas propagandas", que terão como "única paixão o amor pela pátria"; somente por esse caminho é possível "estabelecer uma sociedade justa" (BURGELIN, 2003, p. XXII).

Rousseau entendia que pelo "contrato social" os cidadãos vivenciariam sua "liberdade no plano político" por meio da "independência natural própria de cada indivíduo", sem qualquer restrição "à livre iniciativa", a qual se transformaria em "soberania quando expressa na vontade geral". Entretanto, para que esta "vontade" fosse organizada e apresentada de modo consciente, era necessário "educar os homens" 
que iriam "atuar e viver sob esse contrato", pois, "quanto mais presente estiverem as opiniões dos cidadãos", esta "vontade será melhor formulada". A partir dessa educação e a consequente participação política, os cidadãos "ascendem do plano individual para o plano da existência política nas assembleias", local no qual se "adquire a educação política", bem como se "realiza plenamente a condição de cidadão" (VALDEMARIN, 2000, p. 41-42).

Nesse sentido, a obra Emílio ou Da Educação se caracteriza como uma das "faces daquele contrato político ou a face pedagógica da ação política”. É o "desdobramento prático dos princípios" que constituem o "contrato" em um "ser, desde o nascimento até a idade adulta", pela conciliação entre a "liberdade necessária ao pleno desenvolvimento do indivíduo e a liberdade social", que se constitui como "garantia para o desenvolvimento de todos os homens". No Contrato Social, Rousseau institui o "artifício" que garante "a soberania e a liberdade a todos os homens", e em sua proposta educacional é afiançada a "melhor expressão da vontade geral", condição essencial para que a "soberania" do povo seja concretizada (VALDEMARIN, 2000, p. 42).

Em seu "tratado de educação", Rousseau busca "fixar" como "seria a educação necessária à prática" daquele Contrato. Deste modo, ele idealiza um personagem fictício - Emílio, que lhe permite "projetar o futuro" a partir da "indicação dos princípios políticos transmutados em prática pedagógica". Emílio é concebido como um "ser" no qual "atuam as leis naturais", ou seja, "o impulso para conservação de si e para conservação da espécie", sendo ausente a atuação das "convenções existentes" na sociedade corrompida do século XVIII; justamente por essa situação de corrupção, é que a relação de Emílio com tal sociedade somente ocorrerá pela mediação de seu preceptor, que é o próprio Rousseau (VALDEMARIN, 2000, p. 42-43).

Embora a educação "projetada" por Rousseau nessa obra "atinja plenamente seus objetivos na idade adulta", momento em que vigora o "contrato", ela ocorre durante toda a vida do Emílio, começando em seu nascimento, o que representa uma inovação para a sociedade em que vivia, pois, desde o século XVII era reconhecido que a "educação deveria ter início na mais tenra idade". Entretanto, o "maior mérito" de Rousseau foi transformar os "princípios do contrato em práticas pedagógicas". Após ter “fixado os princípios políticos" pela relação dialética entre liberdade e igualdade para evitar "dependências" entre os cidadãos, Rousseau traz a "inteligibilidade desses princípios" para a educação do Emílio, adequando-a "diferentemente em cada uma das fases da vida" (VALDEMARIN, 2000, p. 43). 
Somente a partir dessa educação seria possível formar o cidadão consciente da importância de sua participação política na vida adulta, momento em irá viver sob o "pacto social". Esse cidadão que Rousseau pretende formar é o "homem total", que é "bem preparado humanamente para resistir aos constrangimentos, vícios e deteriorações próprias da vida social e cônscio de seu dever cívico para com a espécie". Este "tipo de cidadão" é concebido por Rousseau como um "cidadão legítimo" que vive e participa politicamente tanto daquela "sociedade perfeita" que ele idealiza no Contrato Social, quanto de uma sociedade "mais real, cheia de imperfeições, na qual a participação de homens como Emílio poderá contribuir ao seu melhoramento" (PAIVA, 2007, p. 80-81 grifos do autor).

Segundo Paiva (2007, p. 81), este "tipo de cidadão" que Rousseau pretende formar pela educação, que participa ativamente da sociedade, da elaboração das leis no âmbito do poder legislativo, que delibera na assembleia com os demais cidadãos para juntos estabelecerem a "vontade geral", é o que "melhor atende às reais necessidades do homem moderno". De um lado, a "formação do homem como indivíduo lhe concede o equilíbrio pessoal" por meio do "desenvolvimento de sua espiritualidade, do conhecimento de si e de outros atributos naturais", o que lhe possibilita viver "bem consigo e com seus semelhantes"; ao mesmo tempo, esses "atributos pessoais" se transformam em "atributos sociais", pois "ninguém vive sozinho" e, como afirma o filósofo, "o homem e o cidadão não tem outro bem para colocar na sociedade a não ser ele próprio" (ROUSSEAU, 2004, p. 261).

\section{Considerações finais}

O presente trabalho focalizou as reflexões de Charles Edward Lindblom sobre o processo decisório, bem como o conceito de "vontade geral” de Jean-Jacques Rousseau a fim de evidenciar que ao discorrerem sobre esses temas, ambos os autores assinalam a importância da participação política dos cidadãos, bem como a necessidade de educação para que essa participação se concretize (ROUSSEAU, 2003, p. 47).

A princípio, foi apresentado como Lindblom concebe o processo decisório, bem como sua origem e constituição. A seguir, focalizou-se como tal processo ocorre no âmbito das sociedades democráticas, dando ênfase à ideia trazida pelo autor de que a participação política dos cidadãos nesse processo e no "jogo do poder" que o constitui 
requer a educação dos cidadãos. Apesar de em alguns momentos, como nas campanhas eleitorais, os cidadãos exercerem sua participação, esta somente será satisfatória, tendo significado para eles, quando forem educados para participar; somente quando aprenderem na escola a importância de sua participação é que os cidadãos irão assumir uma postura mais ativa e participativa, demonstrando interesse pelas questões políticas presentes na sociedade em que estão inseridos (LINDBLOM, 1981, p. 85).

$\mathrm{Na}$ sequência foi apresentado o conceito de "vontade geral", exposto por Rousseau na obra O Contrato Social, o qual também apresenta reflexões acerca da importância da participação política dos cidadãos, mas nesse caso, para a formalização do mencionado "contrato". Como destaca Rousseau, essa participação se efetivará na elaboração das leis que irão reger esse "contrato", momento em que todos os cidadãos que o integram irão debater nas assembleias com o intuito de chegar a consensos sobre o que é mais conveniente para todos e assim formular aquela "vontade" (ROUSSEAU, 2003, p. 47).

Após apresentar essas reflexões, procurou-se destacar, que à semelhança de Lindblom, Rousseau também assinala que essa participação política dos homens na elaboração das leis, na deliberação para constituição da "vontade geral", requer uma educação que transforme esses homens em cidadãos; essa educação deve estar pautada nos "princípios políticos" daquele "pacto social", a qual irá propiciar a formação de um "homem total”, de um "cidadão legítimo", que é consciente da importância de sua participação política e formulação daquela "vontade" (PAIVA, 2007, p. 80-81 grifos do autor).

\section{REFERÊNCIAS}

BOTO, Carlota. Jean-Jacques Rousseau: Biografia Intelectual. Intérprete da política e da infância. Revista Educação, série História da Pedagogia (Jean-Jacques Rousseau), São Paulo, n. 5, p. 6-17, dez., 2010.

BURGELIN, Pierre. Prefácio. In: ROUSSEAU, Jean-Jacques. O contrato social. Tradução Antônio de Pádua Danesi. São Paulo: Martins Fontes, 2003.

FRANCISCO, Maria Fátima Simões. O Nascimento do Ideário Político Contemporâneo. Revista Educação, série História da Pedagogia (Jean-Jacques Rousseau), São Paulo, n. 5, p. 20-31, dez., 2010. 
LINDBLOM, Charles Edward. O processo de decisão política. Tradução Sérgio Bath. Brasília. Editora Universidade de Brasília (UnB), 1981.

PAIVA, Wilson Alves. A formação do cidadão na obra de Jean-Jacques Rousseau.

Fragmentos de Cultura, Goiânia, v. 17, n. 1/2, p. 77-92, jan./fev. 2007.

ROUSSEAU, Jean-Jacques. Discurso sobre a origem e os fundamentos da

desigualdade entre os homens. Tradução Maria Ermantina Galvão. São Paulo: Martins Fontes, 1999.

ROUSSEAU, Jean-Jacques. O contrato social. Tradução Antônio de Pádua Danesi. São Paulo: Martins Fontes, 2003.

ROUSSEAU, Jean-Jacques. Emílio ou Da educação. Tradução Roberto Leal Ferreira. São Paulo: Martins Fontes, 2004.

VALDEMARIN, Vera Teresa. Educação e política ou sobre a possibilidade de efetivar princípios. In: VAIDERGORN, José. (Org.). O direito a ter direitos. Campinas:

Autores Associados, 2000.

\section{Como referenciar este artigo}

SBRANA, Roberta Aline et al. O processo decisório em Charles Edward Lindblom e a vontade geral em Jean-Jacques Rousseau: reflexões acerca da participação política e da necessidade de educação para essa participação. Revista on line de Política e Gestão Educacional, Araraquara, v.21, n.2, p. 467-488, maio-ago. 2017. Disponível em: <http://dx.doi.org/10.22633/rpge.v21.n.2.2017.9479>. ISSN: 1519-9029.

Submetido em: 01/03/2017

Aprovado em: 20/06/2017 